\title{
REMOÇÃO DE FAVELAS ${ }^{1}$
}

\section{REMOVAL OF SLUMS}

\section{Ricardo Cesar Pereira Lira ${ }^{2}$}

\section{Resumo}

O texto a seguir foi proferido em palestra no Fórum de Direito da Cidade da Escola de Magistratura do Rio de Janeiro, razão pela qual não constam referências bibliográficas. O autor, inicialmente, disserta acerca das balizas históricas que nortearam a urbanização brasileira a partir da segunda metade do século XX e se refletiram na então capital da República, impactando até os dias atuais. Destacam-se problemas de cunho estrutural, socioeconômicos, acentuados pela rápida industrialização e pela falta de planejamento, que conduziram à crescente favelização da população de baixa renda, em particular, na cidade do Rio de Janeiro. O autor defende que, a autoconstrução sintetizando a favela, configura-se no cenário urbano como uma solução para a ausência de respeito ao direito à moradia adequada, mas se desdobra em graves consequências para a harmonia do tecido social urbano. Dentre outros exemplos, o autor ilustra o perverso processo de segregação espacial, ensejando a remoção e a "gentrificação" pertinente à dinâmica especulativa imobiliária. Todos invocam inúmeras chagas sociais que the são correspondentes. Defende, como possíveis soluções para gerir o problema habitacional urbano, a conjugação de dois caminhos: um de ordem política, configurando-se em uma espécie de pacto social; outro, valer-se do instrumental jurídico pertinente. Destarte, caminha pelo ordenamento jurídico nacional, a exemplo do Estatuto das Cidades, diploma que dialoga com as premissas constitucionais que lhe dão inspiração, dispondo de uma gama de institutos passíveis de mitigar o referido problema, mas que ainda carecem da pertinente efetividade. Outrossim, incursiona pela questão da regularização fundiária, donde ganha relevo o programa Minha Casa Minha Vida, objeto da Lei n 11.977, de 07 de junho de 2009, para assentamentos de população de baixa renda localizados em área urbana. Tal programa prescinde da intervenção do Poder Judiciário, otimizando o procedimento. Estas são, em linhas gerais, a abordagem do presente texto.

Palavras-chave: Direito à moradia. Regularização fundiária. Remoção. Gentrificação.

\section{Abstract}

The text to be followed text was given in a lecture at the City Law Forum of School of Magistracy of the State of Rio de Janeiro, which is why there are no bibliographical references. The author initially talks about the historical beacons that guided brazilian urbanization from the second half of the twentieth century and were reflected in the then capital of the Republic, impacting until the current days. Be noteworthy structural, socioeconomic problems, accentuated by the rapid industrialization and the lack of planning, which led to the increasing slackening of the low-income population, particularly, in the city of Rio de Janeiro. The author argues that, the self-construction synthesizing the favela, is configured in the urban scenario as a solution to the

\footnotetext{
${ }^{1}$ Este texto foi resultante de palestra proferida pelo professor Ricardo Pereira Lira no Fórum Permanente de Direito das Cidades da Escola de Magistratura do Estado do Rio de Janeiro (EMERJ), em 03 de outubro de 2016, razão pela qual não contém referências. Participaram da mesa o Des. Marcos Alcino de Azevedo Torres, na qualidade de presidente, e os advogados Frederico Price Grechi e José Ricardo Pereira Lira.

2 Professor emérito da Faculdade de Direito da Universidade do Estado do Rio de Janeiro - UERJ. E-mail: rlira@uninet.com.br
} 
lack of respect for the right to adequate housing, but unfolds in serious consequences for the harmony of the urban social fabric. Among other examples, the author illustrates the perverse process of spatial segregation, leading to the removal and "gentrification" pertinent to estate speculative dynamics. All invoke numerous social wounds that correspond to him. He defends, as possible solutions to manage the urban housing problem, the conjugation of two paths: one of political order, being configured in a kind of social pact; another, to use the relevant legal instruments. Thus, it addresses the national legal system, such as the Statute of Cities, a diploma that dialogues with the constitutional premises that give it inspiration, having a range of institutes that can mitigate this problem, but which still lack the pertinent effectiveness. He also ventures into land regularization, where gains prominence the My House My Life program, object of Law no. 11.977, dated June 7, 2009, highlighted for low-income settlements located in urban areas. This program dispenses with the intervention of the Judiciary, optimizing the procedure. These are broadly the approach of this text.

Keywords: Right to adequate housing. Land regularization. Removal. Gentrification.

\section{O ARGUMENTO HISTÓRICO}

O tema está visceralmente ligado ao inchaço populacional nos centros urbanos e nas metrópoles. Tal inchaço, como venho afirmando em inúmeros trabalhos, se deve fundamentalmente às seguintes circunstâncias:

a. à maneira desordenada como se deu, em 1888, a abolição da escravatura. A emancipação dos escravos foi simplesmente formal, sem nenhuma assistência aos libertos, que thes proporcionasse as mínimas condições de uma vida digna. Alguns permaneceram abandonados na zona rural, outros tantos se dirigiram aos centros urbanos, ocupando-os sem a mais mínima racionalidade;

b. a segunda causa está no fim da chamada Guerra de Canudos, grave conflito ocorrido no sertão da Bahia. Dizimados Antônio Conselheiro, líder da rebelião, e seus sequazes, as tropas regulares voltaram às suas bases e se assentaram no perímetro urbano do Rio de Janeiro, de maneira inteiramente desordenada;

c. a terceira causa da intensificação demográfica nos centros urbanos foi a industrialização. O Brasil era um país eminentemente rural. A partir dos anos 30 do século passado, iniciou-se topicamente a industrialização, como resultado da promulgação do primeiro Código de Águas e do primeiro Código de Minas. Pelo primeiro código mencionado, as quedas d'água de maior volume passaram a ser propriedade da União Federal, propriedade distinta da propriedade do solo. Tais quedas d'água passaram a ser objeto de concessões federais, com a finalidade de 
exploração de energia elétrica. Com a edição do Código de Minas, as jazidas minerais passaram a ser de propriedade da União Federal, e também passaram a ser objeto de concessões federais, para exploração da riqueza mineral. Esses fatos consubstanciaram os primórdios da industrialização.

No começo dos anos 40 do século passado, em plena Segunda Guerra Mundial, quando o Presidente Getúlio Vargas já havia decidido apoiar os aliados na luta contra o nazi-fascismo, o Presidente dos Estados Unidos da América do Norte, Franklin Delano Roosevelt, solicitou um encontro com o nosso Presidente. Esse encontro ocorreu em Natal. O que o líder estadunidense desejava era a autorização do governo brasileiro para construir bases aéreas no Norte e no Nordeste brasileiro, nas quais aviões militares norte-americanos pudessem pousar, para em seguida retomar voo para Dakar, no norte da África, onde acontecia intenso combate entre tropas chefiadas pelo Almirante inglês Louis Mountbatten e o General alemão Erwin Rommel, a Raposa do Deserto. Os aviões norte-americanos não tinham autonomia de voo para alcançar diretamente Dakar.

Nessa ocasião os Estados Unidos da América do Norte proibiam a fabricação de aço no Brasil, para que importássemos todo o aço de que precisássemos. A hegemonia militar e econômica da grande potência permitia a imposição dessas restrições.

O Presidente Getúlio Vargas, político muito hábil, respondeu positivamente às pretensões do Presidente Roosevelt, asseverando que concordaria com a construção e operação das bases norte-americanas em nosso território, sob as seguintes condições:

a. que os EEUU dessem ao Brasil os recursos necessários para a implantação de uma usina siderúrgica em nosso país;

b. nos transferissem toda a respectiva tecnologia.

Assim se fez, e nasceu a Companhia Siderúrgica Nacional. Implantou-se, também, à época, a Companhia Vale do Rio Doce, para exploração de minério. Deu-se, dessa maneira, passo decisivo para a industrialização em nosso país.

Nos anos 50 do século passado, incrementou-se significativamente a industrialização, com o Plano de Metas do Presidente Juscelino Kubitscheck, voltado sobretudo para a indústria automotiva.

Como dizem os planejadores urbanos, a toda industrialização corresponde necessariamente uma urbanização. 
Pari passu com essa industrialização verificava-se um natural crescimento demográfico nos centros urbanos em um gradiente de aumento de 3\% da população. Todas essas circunstâncias determinaram uma crescente urbanização.

Ocorriam também migrações, operando-se no sentido Nordeste-Sudeste, com uma ocupação inteiramente desordenada dos centros urbanos. Posteriormente, tais migrações se tornaram pluridirecionais.

As populações migrantes, constituídas por pessoas de baixa renda, se assentavam, basicamente, nas periferias das cidades. No Rio de Janeiro, os migrantes se instalaram não só nas periferias, como no perímetro urbano e nos picos e ribanceiras dos morros, em razão da sua topografia específica.

Finalmente, deve ser apontada como causa desse adensamento populacional nas cidades e nas regiões metropolitanas, a falta de uma política pública consistente na busca da permanência do homem na zona rural, ou seja, a falta de uma reforma agrária, explicando-se o assentamento desordenado nos centros urbanos, pela ausência de vontade política para realização de uma reforma urbana.

Ainda hoje a reforma agrária e a reforma urbana são realidades inatingidas.

\section{COROLÁRIOS}

Esse inchaço populacional nas cidades, com a ocupação desordenada, irracional e injusta do solo urbano, traz consequências altamente danosas. Tal ocupação acontece caracterizada pela segregação residencial, pela exclusão social, pelo déficit habitacional, pela deficiência na qualidade dos serviços públicos, e, também, pela utilização predatória do meio ambiente natural, pela deficiência de serviços de transporte, causando a falta de mobilidade urbana, com o estresse consequente. Faz-se, ainda, caracterizada pela deslegitimação da autoridade pública, fomentando um sentimento generalizado de impunidade, inclusive nas classes abastadas, como episódio ocorrido algum tempo atrás em Brasília, quando jovens da alta classe média, entre eles o filho de um magistrado, atearam fogo em um índio pataxó que dormia no banco de uma praça. Mais recentemente atearam fogo em uma doméstica, pensando que fosse uma prostituta, como se assim fosse, tal comportamento se justificasse. Ainda mais recentemente, na Avenida Paulista, na cidade de São Paulo, três adolescentes agrediram violentamente um homossexual, causando-lhe graves lesões corporais. E o que é tão preocupante: o agente policial se deixa corromper, dominado pelos traficantes e milicianos. É 
de pasmar que traficantes e milicianos tentem participar da vida política, infiltrando-se nas organizações partidárias e elegendo-se vereadores e deputados.

Qual a solução para enfrentar esses problemas?

A primeira delas seria a consciência coletiva da necessidade de acertamento. O desejo real, o forte sentimento coletivo da necessidade de erradicação desses males. A opinio necessitatis, ou seja, a consciência de todos da indispensabilidade da eficácia social do sistema normativo, buscando o desaparecimento dessas disfunções. Impõe-se, ainda a férrea vontade política de quem tem o poder de modificar o status predominante.

A segunda seria a disponibilidade de instrumentos jurídicos necessários para tanto. Esses instrumentos já existem. O artigo 21, inciso XX, da Constituição Federal de 1988, estatui competir à União Federal "instituir diretrizes para o desenvolvimento urbano, inclusive habitação, saneamento básico e transporte urbano".

Essa mesma Constituição, no Título VII, tratando da Ordem Econômica e Financeira, sob a epígrafe "Política Urbana", nos artigos 182/183, contempla, pela primeira vez, na história constitucional brasileira, a cidade, determinando os pilares da sua função social, explicitada pelo direito universal à cidade, pela gestão democrática dos interesses urbanos e pela função social da propriedade urbana.

Vale salientar que no plano infraconstitucional já existiam instrumentos jurídicos buscando o ordenamento urbano. Nessa esteira, é de ser lembrado, pela sua importância, o instrumento citado pelo art. 70, do Decreto-Lei $n^{\circ}$ 271, de 28 de fevereiro de 1967, nomeadamente a concessão de direito real de uso. Esse instrumento está assim definido:

Art. 7o - É instituída a concessão de uso de terrenos públicos e particulares, remunerada ou gratuita, por tempo certo ou indeterminado, como direito resolúvel, para fins específicos de urbanização, industrialização, edificação, cultivo da terra, ou outra utilização de interesse social.

Note-se que com a aplicação desse instituto o concessionário não obtém a propriedade, mas tão somente a posse.

As diretrizes federais com vistas ao urbanismo e instrumentos para implementá-las, prometidas pela Constituição de 1988, tiveram formulação muito demorada no Congresso Nacional.

Terminaram editadas pela Lei Federal $n^{\circ}$ 10.257, de 10 de julho de 2001, complementada pela medida provisória $n^{0}$ 2220, de 04 de setembro de 2001, a primeira consubstanciando o denominado ESTATUTO DA CIDADE, e a segunda criando a concessão de direito real de uso para fins de moradia, que constava originalmente nos artigos 15 a 20 do 
Estatuto da Cidade e foram vetados pelo Presidente Fernando Henrique Cardoso, que, consequentemente, alguns meses depois, baixou a referida medida provisória.

Alinhem-se algumas das diretrizes enunciadas no artigo 2o, do Estatuto da Cidade, sem prejuízo da relevância das demais:

a. efetivar a garantia do direito a cidades sustentáveis, entendido como o direito à terra urbana, à moradia, ao saneamento ambiental, à infraestrutura urbana, ao transporte e aos serviços públicos, ao trabalho e ao lazer, para as presentes e futuras gerações;

b. gestão democrática por meio da participação da população e de associações representativas dos vários segmentos da comunidade na formulação, execução e acompanhamento de planos, programas e projetos de desenvolvimento urbano;

c. oferta de equipamentos urbanos e comunitários, transporte e serviços públicos adequados aos interesses e necessidades da população e às características locais;

d. combate à retenção especulativa de imóvel urbano, que resulte na sua subutilização ou não utilização;

e. justa distribuição dos benefícios e ônus decorrentes do processo de urbanização;

f. regularização fundiária e urbanização de áreas ocupadas por população de baixa renda mediante o estabelecimento de normas especiais de urbanização, uso e ocupação do solo e edificação, consideradas a situação socioeconômica da população e as normas ambientais.

As diretrizes gerais estabelecidas pelo Estatuto da Cidade são de ser observadas nas regiões metropolitanas por força do artigo 7ํㅡ, do Estatuto da Metrópole (Lei Federal $n^{\circ}$ 13.089, de 12 de janeiro de 2015).

Os instrumentos constantes do Estatuto da Cidade são o plano diretor, o parcelamento, edificação ou utilização compulsórias, a usucapião de imóvel urbano singular ou coletivo, a concessão de uso especial para fins de moradia, o direito de superfície, o direito de preempção, a outorga onerosa do direito de construir, as operações urbanas consorciadas, a transferência do direito de construir, o estudo de impacto de vizinhança e a gestão democrática da cidade.

Não era possível, em nome da brevidade, a enunciação do conceito de cada um desses instrumentos. Ela, contudo, poderá ser encontrada em trabalhos do autor deste texto, como, por exemplo, "O Direito Formal e Informal nos Centros Urbanos Brasileiros". Qualquer interessado poderá, para tanto, acessar na internet o site <www.institutas.com.br $>$ por Ricardo Pereira Lira. 


\section{A TERRA É O NÓ}

O assentamento irregular no solo urbano provoca a exclusão social nas cidades e metrópoles, ocorrendo o que se chama "segregação residencial", verificando-se o que os planejadores urbanos, sociólogos e antropólogos denominam "gentrificação".

Gentrificação (do inglês gentrification) é o fenômeno que afeta uma região ou bairro pela alteração da dinâmica da composição do local, tal como novos pontos comerciais ou construção de novos edifícios, valorizando a região, e afetando a população de baixa renda local. Tais processos são criticados por alguns estudiosos do urbanismo e do planejamento urbano devido ao seu caráter conservador e sem compromisso com o social, Outros estudiosos, como o sociólogo Richard Sennett, da Universidade de Harvard, consideram demagógico o caráter dessas críticas, argumentando que problemas urbanos não se resolvem com benevolência para com as camadas mais pobres da população e, na sua opinião, só se resolvem com alternativas que reativem e recuperem a economia do local degradado.

O vocábulo "gentrificação" não se encontra nos dicionários correntes. A noção de gentrificação está intimamente ligada à questão da remoção das favelas. Arquitetos há que consideram as favelas um problema, quando em verdade, o favelamento é uma solução. Não deixa de ser uma forma de, embora precariamente, assegurar o direito de moradia para as populações de baixa renda.

A remoção de favelas, política que entre nós prevaleceu nos anos 60 do século passado, cria uma realidade altamente negativa, socialmente desastrosa.

Isso aconteceu com a remoção da favela da Catacumba, erradicada para que no local se instalassem edifícios sofisticados, para moradia de pessoas abastadas. Essa favela ficava à beira da Lagoa Rodrigo de Freitas, no Rio de Janeiro.

As autoridades mandaram atear fogo na favela, sendo que, pelo menos, tiveram a misericórdia de retirar as famílias que ali moravam.

As famílias dos favelados se dividiram. As mulheres, com suas filhas, foram removidas para muito longe, para Antares e Santa Cruz. Os chefes de casal, operários que eram, ficaram nos canteiros de obra, onde trabalhavam, nos bairros de Ipanema e Leblon. Isso debilitou os orçamentos das pobres famílias, sendo que para a recuperação financeira do grupo, as meninas de 10, 11 e 12 anos de idade tiveram de prostituir-se!!! 
Caso concreto e dilacerante de verdadeira gentrificação, ou seja desalojamento arbitrário de população de baixa renda, em benefício de pessoas afortunadas, que se acomodaram, no local, em luxuosos prédios!!!

Sempre o capitalismo selvagem sacrificando os mais pobres!!!

Posteriormente passou a prevalecer uma política nobre, dominada pela função social da cidade, pelo sentimento de fraternidade, buscando a urbanização das favelas e reconhecendo a necessidade de existência de uma moradia adequada para todos.

Tal orientação se concretizou nas disposições constantes da Constituição Federal de 1988, contemplando um capítulo especial sob a epígrafe "Da Política Urbana", estabelecendo que apolítica de desenvolvimento urbano, executada pelo Poder Público Municipal, conforme diretrizes gerais fixadas em lei, tem por objetivo ordenar o pleno desenvolvimento das funções sociais da cidade e garantir o bem-estar de seus habitantes.

Com a Emenda Constitucional $n^{\circ} 26$, de 14 de fevereiro de 2000, a moradia foi incluída entre os direitos sociais, como elemento fundamental da assistência aos desamparados.

Essas diretrizes gerais foram baixadas, como já referido, com o Estatuto da Cidade (Lei Federal $n^{\circ}$ 10.257, de 10 de julho de 2001), destacando-se, entre elas, a que determina "a regularização fundiária e urbanização das áreas ocupadas por população de baixa renda, mediante o estabelecimento de normas especiais de urbanização, uso e ocupação do solo e edificação, considerada a situação sub econômica da população e as normas ambientais".

A Lei Orgânica do Município do Rio de Janeiro, de 05 de abril de 1990, estatui no seu artigo 429, que a política de desenvolvimento urbano respeitará vários princípios, entre eles a urbanização, a regularização fundiária e titulação das áreas faveladas e de baixa renda, sem remoção dos moradores, salvo quando as condições físicas da área ocupada imponham risco de vida aos seus habitantes, hipótese em que serão seguidas as seguintes regras:

a. laudo técnico do órgão responsável;

b. participação da comunidade interessada e das entidades representativas na análise e deliberação das soluções;

c. assentamento em localidades próximas dos locais de moradia ou do trabalho, se necessário o remanejamento.

O Governo Federal em 2009, concebeu o Programa Minha Casa Minha Vida, objeto da Lei $n^{\circ}$ 11.977, de 07 de junho de 2009, dispondo sobre a regularização fundiária de assentamentos de população de baixa renda localizados em área urbana e, de maneira desjudicializada, isto é, sem intervenção do Poder Judiciário. 
Esse diploma legal, no artigo 50, dispõe que a regularização fundiária consiste no conjunto de medidas jurídicas, urbanísticas, ambientais e sociais que visam à regularização de assentamentos urbanos e à titulação de seus ocupantes, de modo a garantir o direito social à moradia, o pleno desenvolvimento da função sociais da propriedade urbana e o direito ao meio ambiente ecologicamente equilibrado.

No artigo 58, cuida especificamente da regularização fundiária de interesse social, estatuindo que o projeto de regularização fundiária deverá considerar as características de ocupação e da área ocupada para definir parâmetros urbanísticos e ambientais, além de identificar os lotes, as vias de circulação e as áreas destinadas ao uso público.

A iniciativa pode ser do Poder Público em geral, que providenciará um auto de demarcação urbanística, com as características definidas em lei.

O auto será encaminhado ao registro de imóveis, que fará as buscas para identificar eventual proprietário da área a ser regularizada.

Inocorrendo qualquer impugnação por parte de proprietário identificado, a demarcação será registrada. Haverá parcelamento, e após o respectivo registro, o Poder Público outorgará o título de legitimação da posse aos ocupantes cadastrados, constituindo a legitimação da posse, devidamente cadastrada, direito de posse direta para fins de moradia em favor do respectivo outorgado.

Afirma o artigo 65, da mencionada lei, que "sem prejuízo dos direitos da posse exercida anteriormente, o detentor do título de posse, após cinco anos de sua averbação, poderá requerer ao oficial do registro de imóveis conversão desse título em registro de propriedade, tendo em vista sua aquisição por usucapião, nos termos do artigo 183 da Constituição".

A Lei Federal n 11.977, de 2009, foi alterada pela Medida Provisória nº 514, de 2010, porém o desenho da legitimação da posse convertida em propriedade não sofreu qualquer modificação.

Talvez fosse o caso de simplificar a solução trazida pelo Programa Minha Casa, Minha Vida, com três pequenas alterações no artigo 65, e que seriam as seguintes:

a. reduzir o prazo da transformação da posse legitimada em propriedade para dois anos, tornando mais célere essa convolação;

b. tornar efetiva esse convolação em propriedade independentemente de requerimento do outorgado, tornando-se essa transformação realidade pelo simples decurso do prazo, ministério legis; 
c. eliminar a referência ao instituto da usucapião, que só abre oportunidade para que mentes conservadoras venham oferecer, na aplicação da lei, empecilhos para a titulação das áreas ocupadas pela população de baixa renda. Nada impede que logo após o final do prazo, que seria de dois anos, a posse legitimada, ope legis, se transforme em propriedade.

\section{CONSIDERAÇÕES FINAIS}

É inegável a importância da solução trazida pela Lei n 11.977, de 2009, que busca dar concretude e eficácia social ao artigo 6º da Constituição Federal de 1988, na conformidade da Emenda Constitucional $n^{\circ} 26$, de 14 de fevereiro de 2000, que consagra a moradia como um direito social fundamental, sempre atenta ao princípio, também fundamental, da dignidade da pessoa humana.

Igualmente relevante o procedimento de desjudicialização estipulada pela Lei 11.977, de 2009, que torna a solução do problema da moradia do pobre livre das demoras e implicações necessariamente complexas quando o desate da questão é submetido ao Poder Judiciário.

Vale lembrar que quando se fala em moradia, se está pensando em moradia adequada.

O direito à moradia integra o direito a um padrão de vida adequado. Não se resume apenas a um teto e quatro paredes, mas ao direito de toda a pessoa ter acesso a um lar e a uma comunidade apta a ensejar paz, dignidade e saúde física e mental.

A moradia adequada deve incluir segurança da posse, disponibilidade de serviços necessários, infraestrutura e equipamentos públicos, custo acessível, habitabilidade, não discriminação de grupos vulneráveis, localização adequada e adequação cultural.

O que é finalmente importante é que todos os diplomas legais acima referidos tenham eficácia social.

Dessa maneira se alcançará uma sociedade livre, republicana, democrática, justa e solidária, erradicando-se a pobreza, e eliminando as desigualdades sociais, bem como promovendo o bem de todos, sem preconceito de raça, origem, sexo, cor e idade.

Tudo em nome da dignidade da pessoa humana, como impõem os princípios e postulados constitucionais.

Trabalho enviado em 04 de junho de 2017.

Aceito em 12 de junho de 2017. 